\title{
Consumo e Meio Ambiente
}

\section{Maria Lucia Zülzke}

É com grande alegria que agradeço à Universidade Federal do Rio Grande do Sul è Universidade Pace a oportunidade de me integrar à rede de profissionais, aqui presentes, os quais trabalham, refletem, ensinam e atuam em meio ambiente, economia, consumo e articulação da sociedade civil. Meus especiais agradecimentos à Dra. Cláudia Lima Marques, com quem compartilhei a diretoria do Brasilcon, e à Dra. Beverly Kahn, coordenadoras do Congresso.

Nesses últimos 14 anos tenho assessorado empresas a abrirem seus Serviços de Atendimento a Consumidores e, também, coordeno cursos para profissionais abordando os aspectos de qualidade de serviços, habilidades no atendimento aos clientes, os requisitos da lei de defesa do consumidor, assim como os conceitos básicos de responsabilidade social empresarial e os pressupostos de qualidade e ética no setor de atendimento ao cliente.

Eim 1985, com a abertura do regime democrático e, quando 5 empresas disponibilizavam Serviços de Atendimento ao Consumidor no Brasil, coordenei um núcleo de atendimento ao consumidor, denominado Núcleo de Valorização do Consumidor, numa multinacional. Iniciei minha carreira profissional etn 1976, concomitante com a abertura do Procon-SP e, por essas razões, a menção de Dra. Cláudia Lima Marques ao meu pioneirismo

\footnotetext{
Formada em Engenhaxia de Alimentos, pela Unicamp, trabalhou no Procon-SP, entre 1976 a 1985 , como coordenadora da Área de Alimentos, de Pesquisas Técricas e foi vice-diretora etn duas gestões. No início de abril de 1985 passou a chefiar o Núcleo de Valorização do Consumidor de multinacional quimica, numa função equivalente a "Ombudsman do Consumidor". Publicou livto sobre a experiencia " $A$ bxindo a empresa para o consumidor - a impoxtância de um canal de atendimento", Ed. Qualitymark, 2 edições, esgotado. A partir de 1991, como sócia diretoxa da MLZ Interação Empresa/Cliente, assessora empresas na criação e implententação de Serviço de Atendimento ao Consumidor com enfoque eto qualidade de serviços e excelência no atendimento a clientes, além de ministrat cursos e palestras. Fó gerente no Instituto Ethos de Emptesas e Responsabilidade Social to ano de 2000.
} 
em assuntos que, nessas últimas 3 décadas, tornaram-se de grande relevância na nossa estrutura política, econômica, social e empresarial.

Nesse período do ano, por estarmos próximos ao Dia Internacional do Meio Ambiente, observamos acontecer vários eventos relacionados ao desenvolvimento sustentável. Gostaria de mencionar o Congresso Ibero-Americano sobre Desenvolvimento Sustentável que mobiliza o setor privado - CEBDS - Conselho Empresarial Brasileiro para o Desenvolvimento Sustentável etn parceria com a Unesco, Governo Brasileiro, PNUMA, World Business Council for Sustainable Development - WBCSD, os 14 BCSD LatinoAmericanos e da Espanha, Portugal e Moçambique. No evento fot oficialmente lançada a Década da Educação para o Desenvolvimento Sustentável e, para o período de 2005 a 2014 , foi instituída, pela ONU, a Década das Nações Unidas para o Desenvolvimento Sustentável, a fim de consolidar os progressos nos campos da educação e da formação dos recursos humanos em sustentabilidade e respeito à diversidade cultural.

No primeiro semestre do ano 2000 iniciaram-se fortes movimentos do Global Compact, no Brasil, por meio do Instituto Ethos de Empresas e Responsabilidade Social, que mobilizou as indústrias com preocupações ecológicas c sociais; a comunidade empresarial para as ações de responsabilidade social e, consequentemente, a formação e ampliação da rede de executivos, cientistas e estudiosos que atuam sistemicamente no mercado com compromissos de lucro porém, com simultânea qualidade de produtos e serviços, com incorporação de responsabilidade social empresarial. $O$ desafio aos empresários foi lançado oficial e mundialmente, em 26 de julho de 2000, pelo secretário-geral das Nações Uniđas, Kofi Annan.

Dos princípios relacionados ao meio ambiente, 3 dizem que as empresas devem

7. dat apoio às abordagens preventivas nos desafios ambientais;

8. promover iniciativas que ampliem suas responsabilidades ambientais;

9. estimular o desenvolvimento e difusão das tecnologias mais amigáveis em termos do meio ambiente.

Dos seus desdobramentos no Brasil, registram-se que, em dezembro de 2003, foi realizado em Minas Gerais, o III International Global Compact Learning Forum Meeting para troca de experiências e a regionalização das redes e, em novembro de 2004, em Curitiba, aconteceu o Fórum de Aprendizado do Pacto Global com 229 organizações brasileiras signatárias do compromisso.

O Instituto Ethos de Empresas e Responsabilidade Social também conta com inúmeras publicações que podem ser conseguidas acessando o site www.ethos.org.br, como "O Compromisso das empresas com o Meio Ambiente" - uma proposta de agenda ambiental das empresas. Outras publicações que teriam conexão com nosso tema é a Pesquisa sobte consumidor e responsabilidade social empresarial, cujo primeiro número, no ano 2000 , teve a minha direta colaboração, e o Manual sobre redução de desperdícios de alimentos. 
Gostatia, também de compartilhar com vocês, que em 01 de abril de 2005 , a Secretaria do Meio Ambiente do Estado de São Paulo realizou o "Seminário Internacional sobre a Avaliação Ecossistêmica do Milênio", apresentando o relatório lançado oficialmente pela Organização Pan-Americana de Saúde, no dia 30 de matço de 2005, em Brasília, o qual permite conhecer os prognósticos das conseqüências das relações existentes entre meio ambiente e bem-estar humano. Os interessados podem acessar o site www.maweb.org/en/ index.aspx.

A avaliação Ecossistêmica do Milênio foi desenvolvida entte 2001 e 2005 para estabelecer a base científica das ações necessárias 'a melhoria, à conservação e ao uso sustentável dos ecossistemas e suas contribuições para o bem-estar humano. Os serviços dos ecossistemas dos quais os cidadãos se beneficiam: abastecimento de água e alimentos; a madeira e a fibra para energia; setviços culturais que proporcionam beneficios recreativos, estéticos e espirituais; o ciclo nutricional entre outros fluxos de serviços dos ecossistemas que afetam o clima, as inundações, a seca, os resíduos, as doenças e a qualidade da água etc. De acordo com o relatótio -" "Durante os próximos 50 anos, as projeções indicam que a demanda por alimentos deve crescer entre 70 e $80 \%$, e a demanda por água entre 30 e $85 \%$. Em países em desenvolvimento, a captação de água deve aumentar significativamente." "A segurança a limentar não será alcançada, de acordo com os cenários da Avaliação Ecossistêmica, até o ano de 2050 e será difícil erradicar a subnutrição infantil’' Várias perspectivas promissoras ou negativas são apresentadas no telatório. Os líderes mundiais apelam para que a perda da divetsidade biológica seja reduzida até 2010 .

O professor Batton Thompson, da Faculdade de Direito de Stanford, que nos precedeu nesta tarde, em sua excelente exposição sobre "Barreiras Psicológicas na Proteção do Meio Ambiente", enfatiza estudos que poderíamos também entender como dilemas éticos - fazemos ou não escolhas presentes para ganhos potenciass no futuro?

Uma das primeiras oportunidades que me lembro de ter sido provocada sobre dilemas éticos, en consumo e meio ambiente, foi numa palestra tealizada em meados de 1986, portanto há 19 anos, pelo Sr. Johannes Jaschick, na época secretário geral da Confederação dos Consumidores da Alemanha, e que veio ao Brasil a convite do Instituto Goethe, do Rio Grande do Sul.

Em sua brilhante exposição o Sr. Johannes Jaschick ressaltou a importância das matas aos sistemas hídricos, visto que os ecossistemas estão conectados porém, lamentava que as matas não tinham significado nos números e índices das economias mundiais. Dizia ele : as matas só surgem nos livros de contabilidade gerando riquezas quando estimulam a compra de moto- serras, quando geram empregos e são transformadas em madeira a ser comercializada. Só nessas circunstâncias é que se entende que as matas trazem desenvolvimento econômico.

Ele continuava: Quando um parque, por exemplo, é transformado em estacionamento pode-se quantificar, em dinheiro, o rendimento da átea liberada pelas árvores para a ocupação 
dos veículos. Portanto, dentro do nosso entendimento de riquezas, as florestas e matas não são ativos por si mesmas. Mas quem contabiliza os danos resultantes da destruição das matas e dos rios? Do empobrecimento e contaminaçăo dos solos? Da poluição do at? Das denominadas externalidades negativas?

Só será possível optar pela manutenção do parque se, o othar sobre o impasse empresarial, fizet cálculos baseados na Econotnia Ecológica, a qual quantifica o valor dos produtos e serviços sob a ótica da renovabilidade das fontes energéticas e dos materiais, além de trabalhat com escolhas, que consideram o bem estar da população e as consequências dos fluxos de serviços dos ecossistemas no desenvolvimento sustentável e, näo apenas os retomos financeiros de curto prazo

Verificamos que o Direito ao Consumo proporciona uma demanda específica de grupos de cidadãos que compram - consumidores, a ser confrontado com o Direito Ambiental, de caráter difuso e coletivo que, como muito bem explica o juiz Dr. Eládio Lecey, em sua palestra "Responsabilidade Penal da pessoa jurídica:efetividade e questôes processuais", apresentada no $8^{\circ}$ Congresso Internacional de Direito Ambiental e em artigo publicado nos Anais 2004: "O meio ambiente é um bem difuso por excelência. Uma ofensa ao ambiente, embora reflexamente e por vezes de maneira imediata possa atentar contra direitos individuais, como a vida e a saúde das pessoas, atenta contra a coletividade e incide difusamente, não somente com as gerações presentes, mas com as futuras gerações. $O$ meio ambiente é um bem, um autêntico valor, ou melhor, uma riqueza em sì, gerando interesses às pessoas individual e coletivamente consideradas."

A tapidez con que podem ser destruídos os recursos naturais exige monitoramentos e decisōes sábias,pois a recuperação de um dano ambiental pode levar centenas de anos. Estima-se a necessidade de 200 a 300 anos para recuperar uma flotesta de mogno. Dá que o Direito Ambiental mereça um tratamento de prioridade máxima pelos elevadíssimos riscos à coletividade presente e futura e, pela mestma razão, a seriedade das decisões exige o compromisso das empresas ao adotarem iniciativas de auto-regulamentação com os conhecimentos técnicos relacionados à sua atividade.

Por outro lado, nós, consumidores individuais, precisamos de esclarecimentos, educação, alternativas e escolhas no mercado de consumo, além de conhecer as formas de nos articularmos para influenciar nas macro decisões tomadas.

Quando mencionamos consumidor, pensamos nos segmentos de indivíduos com seu poder aquisitivo, suas crenças, experiências, educação e oportunidades; quando mencionamos consumidor, projetamos os perfis de indivíduos e suas circunstâncias, seus aprendizados e as conseqüências de suas atitudes no momento em que toma decisóes de consumo, alinhadas ou não com a responsabilidade empresarial.

O IDEC, nos últimos anos passou a realizar trabalho com o Ministério do Meio Ambiente, e Ministério da Educação e Cultura, para capacitar professores a respeito do Consumo Sustentável, tendo por base Manual de Educação. Os primeiros passos em termos 
de educação formal estão sendo dados. O Instituto Akatu também trabalha com o enfoque do Consumo Sustentáyel assim como outras ONGs, que não irei mencionar para não correr o risco de otnitir injustamente algumas delas.

O que mais ressalta nas semelhanças dos desafios do consumo e do meio ambiente é a importância da prevenção, se é que é possivel pensar em prevenção, etn termos de meio ambiente, ou se o máximo a se obter é um modelo de gestão sócio ambiental responsável e recuperação dos danos já provocados nos ecossistemas.

No mercado de consumo, por vontade ou poder aquisitivo, por escolha ou por necessidade, tanto selecionaremos como dispensaremos muitos milhares ou milhões de objetos de consumo. Podemos passar a nossa vida, feliz ou infelizmente, contratando ou sem jamais experimentar milhares de serviços disponiveis no mercado e, que por seus impactos ecológicos, podemos conscientemente recusar. Mas, todos nós, somos irremediavelmente dependentes da água, do ar, dos alimentos, da energia solar e de outras formas de energia para a manutenção de nossa vida.

As questões de consumo e do meio ambiente tratam de profundos conflitos de interesses, de âmbito econômico, comercial e geo-político.

Vou resumir em tópicos, alguns aspectos funcamentais, para trabalharmos no concreto e evoluit nos estudos da relação consumo e meio ambiente:

a) Aspecto Primeiro: Temos consciência dos impactos ambientais onde transitamos e realizamos o nosso consumo? Como diz a professora Eda Tassara, da USP, a percepção ambiental parte das nossas dimensões sensotiais, a experiência positiva ou negativa de cada consumidor passa a ser parte integrante da sua individuação, de sua história de vida. 'Também nesse sentido, questiona a professora Beate Frank, da FURB - Faculdade Regional de Blumenau -... O quanto somos cientes, o que sabemos da bacia hidrográfica da qual somos dependentes para obtenção do nosso abastecimento de água, diariamente?

b) Aspecto Segundo - a excessiva carga de informação, a dificuldade de decodificação das prioridades para estabelecermos metas - há poucos anos pleiteávamos o direito à informação para os consumidores, mas hoje vivemos com um volume tão grande de informações, às vezes contraditórias, que precisaríamos ser especialistas pata triálas e usá-las em nosso benefício, daí a extrema importância da atuação das entidades, associações e órgãos normativos na defesa dos consumidores. Tanto na área de consumo como nas questões ambientais, os cidadãos podem atuar com articulação mas existem os limites do poder do indivíduo.

c) Aspecto Terceiro - as nossas opções de consumo e o que isso representa de uso de recursos renováveis ou não renováveis, o que reptesenta de desperdícios, descartes e lixos. Se inserirmos os produtos e ambientes de consumo, dentro dos fluxos de energia, de acordo com o noro paradigma $\mathrm{Da}$ Reposição dos recursos naturais usados na produção e nas alternativas de teciclagem dos lixos e descartes da produção, teremos uma outra perspectiva de gerenciar os tecursos e materiais disponíveis no metcado. 
De acordo com as conclusões do Workshop Internacional, realizado em junho de 2004, na Unicamp, em Campinas - S.Paulo, sobre "Estudos em Energia e Ecologia", entendese que é preciso MUDAR AO MÁXIMO POSSíVEL PARA SE USAR RECURSOS RENOVÁVEIS, isto é, deveríamos estabelecer como prioridade global o rápido aprendizado em usar recutsos naturais renováveis. A meta é que "A Humanidade esteja preparada para caminhar para um outro estágio da civilização com menot nível de disponibilidade de recursos. Isso significa novas formas de produção e consumo". Esse procedimento está sendo considerado o ptocedimento padrão a ser adotado pelas próximas gerações.

Os bilhões de habitantes individuais são sócios do planeta, com suas responsabilidades e impactos nos micro sistemas onde atuam, alguns são sócios minoritários e os grupos de poder são os majoritários. Na nossa sociedade humana nos conectamos por interesses comuns, tendo em vista um senso comum quanto ao nosso presente e futuro. Espetamos que o presente de hoje, e o futuro próximo, privilegiem a sociedade e as civilizaçóes com cultura ecológica e sustentável.

Obrigada pela atençẫo. 